\title{
Resource Utilization and Coexistence of Three Species of Pogonomyrmex Ants in an Upper Sonoran Grassland Community
}

\author{
Stephen Robert Hansen* \\ Ecology Program, University of Michigan, Ann Arbor, MI, USA
}

\begin{abstract}
Summary. In an Upper Sonoran Grassland Community, three species of Pogonomyrmex ants coexist. Due to the similarity in their diets and the apparent limitation of food, coexistence is aided by the differential utilization of the available food, according to size and type. Interspecific differences in morphology, physiology and microhabitat nesting sites facilitate this division. Differences in morphology enable the foragers to handle and collect seeds of different size and, consequently, type. Differences in desiccation resistance enable the foragers to be active at different times and, consequently, incorporate different amounts of insect material into their diets. Differences in microhabitat nest sites offers the foragers different proportions of the desired food resource.
\end{abstract}

\section{Introduction}

It has been postulated that in order for several species to coexist in a limited environment, they must differentially use limited resources (Lotka, 1925; Voltera, 1926, 1931; Gause, 1934). Analysis of natural communities has supported this contention (Cody, 1968; Hespenheide, 1966, 1971; MacArthur, 1958, 1972; Rosenzweig and Steiner, 1970; Vance, 1972; Orians and Horn, 1969; Culver, 1970; Brown and Lieberman, 1973). In these studies, the partitioning of the limited resources is facilitated by interspecific differences between competitors.

In an Upper Sonoran Grassland Community, three species of harvester ants, Pogonomyrmex desertorum, $P$. maricopa and $P$. rugosus are found to collect seeds, forage diurnally and nest in the ground. Due to these ecological similarities, resource utilization may play an important role in coexistence. Differential utilization of limited resources can permit coexistence (MacArthur, 1972). Differential utilization of non-limited resources may have an effect on the species ability to acquire limited resources and, therefore, indirectly permit coexistence.

* Present address: Department of Zoology, University of Iowa, Iowa City, IA 52242, USA 
The purpose of this study is to determine the existence of resource partitioning and to elucidate the mechanisms permitting such divisions. Differential resource utilization is an adaptation to limited resources and competitive pressure. Therefore, in order to identify partitioning mechanisms, it is first necessary to show that these causal factors are operating. Despite the lack of specific experimental manipulation, two lines of evidence support the contention of food limitation and competition in this community. First, a very similar community was recently studied and competition for a limited food resource was observed (Davidson, 1977). Second, observation of foragers shows that up to half return unladen and a large degree of interspecific prey item overlap occurs. This information suggests that food is in limited supply and the species are competing for it.

In this community, morphological, behavioral and physiological factors appear most likely to facilitate food partitioning. Interspecific differences in worker size may aid in partitioning food according to size. Uniform weight differences between sympatric species of ants and birds, in natural communities, have been correlated with the use of different size food items (Levins, 1968; Culver, 1972; Hespenheide, 1971). Interspecific differences in microhabitat nest locations may make different food items available to each species. Since ants forage in the vicinity of their nests, the differential availability of usable seed bearing plants may aid in the division of seeds. Interspecific differences in foraging patterns may aid in the division of temporarily available food resources. If some food items become available only during specific periods of the day, only those ants foraging during that period will be able to take advantage of the situation.

\section{Materials and Methods}

Field experiments on food utilization, microhabitat nest selection and foraging patterns were carried out in an Upper Sonoran Grassland study site, located 5 miles southeast of Portal, Arizona, at an altitude of approximately $1,500 \mathrm{~m}$ and about $4,000 \mathrm{~m}^{2}$ in area. The vegetational cover consists of a mixture of snakeweed, Gutierrezia microcephala A. Gray (Compositae), mesquite, Prosopis juliflora var. Torrezana L. Benson (Leguminosae), Ephedra trifurca Parry (Ephedraceae), Acacia constricta Benth (Leguminosae), three awn, Aristida sp. (Gramineae), Cryptantha crassisepala Green (Boroginaceae), Croton sp. (Euphorbiaceae), and Alonia sp. (Compositae) in approximately decreasing order of abundance. The study area contained 186 nests of $P$. desertorum, 54 nests of $P$. maricopa and 20 nests of $P$. rugosus.

To determine if food resources were partitioned by the three ant species, actual utilizations were measured. Five nests of each species, uniformly distributed throughout the study area, were chosen for direct observation. Observations were made over a three month period, June-August, 1973. This period encompassed the major portion of seed collection by the ant species in this community (Bernstein, 1972).

For each nest, the following procedure was followed. Once each day, fifty food items were taken from sequentially returning foragers. These items were separated into insect and seed categories. The seed items were weighed and, subsequently, divided into three categories: small $(<0.6 \mathrm{~g})$, medium $(0.6-1.2 \mathrm{~g})$ and large $(>1.2 \mathrm{~g})$. The most commonly collected seeds were identified to the species level. The small seed category is primarily composed of seeds from a species of grass in the genus, Aristida. The medium seed category is primarily composed of seeds from Ephedra trifurca. The large seed category is primarily composed of seeds from Cryptantha crassisepala.

In order to assess the effect of worker size on food partitioning, the average weight of each species' workers are compared with the weight of their foraged seeds, which are their main food 
items. The mean worker weights for each species was determined by weighing 100 freshly collected, fully hydrated, workers. The mean weight of seeds collected be each species was determined by weighing the seeds actually collected by foragers.

In this and other determinations, between species' differences are determined by an analyses of variance and, subsequent pairwise Student-Neuman-Keuls multiple range test.

To assess the effect of nest location on seed partitioning, the abundance of the most heavily used seed bearing plant species were determined around all nests of each ant species. A series of square quadrats were constructed, with the nest entrance at the center. Within these quadrats, the density of Aristida sp., Cryptantha crassisepala and Ephedra trifurca were measured. It is assumed in this study that the amount of ground cover of a plant species is proportional to the number of seeds produced and, consequently, available to ant foragers. For each quadrat size, the plant densities were averaged over all nests of each ant species.

Interspecific comparisons of these plant abundances should be limited to areas actually foraged by the ants. Seeds outside a species' foraging area are not available and should not be considered. It is, however, extremely difficult to assess actual foraging areas. Colonies do not forage uniformly in all directions. Their activity is restricted to irregularly shaped regions with uneven intensities throughout. Due to time constraints, foraging areas for each nest could not be determined. Therefore, estimates of maximum foraging areas for each ant species were relied upon. These values were determined by observing foragers from five nests of each species. The distance of the forager furthest away from the nest was measured and an average species value calculated. This served as an estimate of maximum foraging distance. The maximum foraging area is estimated as a circle, with a radius equal to the maximum foraging distance. Between species comparisons are limited to quadrats within their maximum foraging areas. In some cases, the outermost regions of the maximum foraging area are not considered. In these distant regions, foraging intensity is low and uneven and is probably not representative of actual availabilities.

In order to assess the effect of foraging pattern on food partitioning, each species' diurnal foraging pattern is compared with the diurnal collection pattern of food items. Daily ant foraging patterns were observed for five nests of each species, throughout the study period. At half hour intervals, the number of foragers departing the nest within 1 min were counted. At this time of the count, surface temperature was also measured. From the food utilization study, the number of foraged seed and insect items were scored as a function of time of retrieval. This data was obtained from five nests of each species, which were observed for 10 days throughout the study period. At half hour intervals, the number and type of food items retrieved during a 2 min period were recorded. This data was then summed over all nests and divided into three time periods: $6: 00-11: 30$ a.m., 11:30-3:30 p.m., and 3:30-8:30 p.m. These time periods coincide with distinct segments of the ants' foraging profiles.

In order to assess whether differences in foraging regimes can be explained by differences in desiccation resistance, survivorship data, $\mathrm{LD}_{50}$ values, were determined for each ant species over a range of temperature and humidity combinations. Mcasurements were made on samples of freshly collected, fully hydrated, live individuals. Immediately preceding treatment, $100 \mathrm{mg}$ of ants were placed in a short glass tube with nylon mesh secured to both ends to prevent escape and to allow air circulating during treatment. For each species, at least 3 or 4 sample tubes were run at each set of conditions and the measurements are reported as an average of these values. The tubes were placed into a system of sealed, connected desiccators, with a constant $2000 \mathrm{cc} / \mathrm{min}$ air flow throughout. The air flow was used to break down any surface insulating air layer present over the surface of the ants, that might prevent the specimens from experiencing the experimental conditions (A hearn and Hedley, 1969). Constant $0 \%$ relative humidity was maintained by passing the air flow through silica gel and monitored be a Serdex Relative Humidity Indicator present in the system. The entire desiccator system was maintained in an incubator, at a constant temperature of 20,40 or $47^{\circ} \mathrm{C}$. Each hour, the tubes were removed from the system and the condition of the individuals were recorded. The $\mathrm{LD}_{50}$ values for each sample were determined by observing the time it takes for $50 \%$ mortality.

\section{Results}

The three Pogonomyrmex species partition the food resource according to size and type (Table 1). Pogonomyrmex desertorum is the major user of small seeds. 
Table 1. Percentage of total collected food items in each food class

\begin{tabular}{lccc}
\hline & $P$. desertorum & $P$. maricopa & $P$. rugosus \\
\hline Large seeds $(1.2 \mathrm{~g})$ & 2.54 & 19.41 & 48.44 \\
Medium seeds $(0.6-1.2 \mathrm{~g})$ & 9.16 & 31.36 & 20.88 \\
Small seeds $(0.6 \mathrm{~g})$ & 85.22 & 30.09 & 25.71 \\
Insects & 3.00 & 19.13 & 4.40 \\
\hline
\end{tabular}

Table 2. Mean weight of seeds utilized by each ant species, for each seed size class

\begin{tabular}{|c|c|c|c|c|c|c|}
\hline Seed class & Ant species & $\bar{x}$ & $s^{2}$ & $n$ & \multicolumn{2}{|c|}{$\begin{array}{l}\text { Significance of utilization } \\
\text { difference between species }\end{array}$} \\
\hline Small seeds & $\begin{array}{l}\text { P.d. } \\
\text { P.m. } \\
\text { P.r. }\end{array}$ & $\begin{array}{l}0.384 \\
0.419 \\
0.588\end{array}$ & $\begin{array}{l}0.031 \\
0.032 \\
0.181\end{array}$ & $\begin{array}{r}112 \\
80 \\
64\end{array}$ & $\begin{array}{l}\text { n.s. } \\
0.01 \\
0.01\end{array}$ & $\begin{array}{l}\text { P.d. -P.m. } \\
\text { P.m. - P.r. } \\
\text { P.d. - P.r. }\end{array}$ \\
\hline Medium seeds & $\begin{array}{l}\text { P.d. } \\
\text { P.m. } \\
\text { P.r. }\end{array}$ & $\begin{array}{l}0.628 \\
0.688 \\
0.794\end{array}$ & $\begin{array}{l}0.083 \\
0.085 \\
0.081\end{array}$ & $\begin{array}{r}36 \\
136 \\
73\end{array}$ & $\begin{array}{l}\text { n.s. } \\
0.05 \\
0.05\end{array}$ & $\begin{array}{l}\text { P.d. -P.m. } \\
\text { P. M. - P.r. } \\
\text { P.d. -P.r. }\end{array}$ \\
\hline Large seeds & $\begin{array}{l}\text { P.d. } \\
\text { P.m. } \\
\text { P.r. }\end{array}$ & $\begin{array}{l}1.391 \\
2.457 \\
2.739\end{array}$ & $\begin{array}{l}0.483 \\
1.947 \\
2.225\end{array}$ & $\begin{array}{r}18 \\
141 \\
206\end{array}$ & $\begin{array}{l}0.01 \\
0.10 \\
0.01\end{array}$ & $\begin{array}{l}\text { P.d. -P.m. } \\
\text { P.m. - P.r. } \\
\text { P.d. -P.r. }\end{array}$ \\
\hline Total seeds & $\begin{array}{l}\text { P.d. } \\
\text { P.m. } \\
\text { P.r. }\end{array}$ & $\begin{array}{l}1.008 \\
2.153 \\
2.820\end{array}$ & $\begin{array}{r}1.112 \\
8.106 \\
13.535\end{array}$ & $\begin{array}{l}200 \\
141 \\
236\end{array}$ & $\begin{array}{l}0.01 \\
0.05 \\
0.01\end{array}$ & $\begin{array}{l}\text { P.d. -P.m. } \\
\text { P.m. -P.r. } \\
\text { P.d. -P.r. }\end{array}$ \\
\hline
\end{tabular}

Table 3. Mean hydrated weights of ant foragers

\begin{tabular}{lcc}
\hline Ant species & Mean forager weight $(\mathrm{mg})$ & Variance \\
\hline$P$. desertorum & 5.84 & 0.109 \\
$P$. maricopa & 8.86 & 0.596 \\
$P$. rugosus & 15.10 & 0.330 \\
& & \\
\hline Species pair & Significance of difference \\
& between means \\
$P$. desertorum $-P$. maricopa & 0.01 & \\
$P$. desertorum $-P$. rugosus & 0.01 & \\
$P$. maricopa $-P$. rugosus & 0.01 & \\
\hline
\end{tabular}

Pogonomyrmex maricopa is the major user of medium seeds and insect items. Pogonomyrmex rugosus is the major user of large seeds. These observations lead to statistically significant interspecific differences when the weight of foraged seeds are considered (Table 2). Both within size categories and totals of all categories, $P$. desertorum uses the lightest seeds, $P$. maricopa uses intermediate weight seeds and $P$. rugosus uses the heaviest seeds. 
Table 4. Abundance of plant types around the nests of each of the ant species

\begin{tabular}{|c|c|c|c|c|c|c|c|}
\hline \multirow[t]{2}{*}{ Plant species } & \multirow{2}{*}{$\begin{array}{l}\text { Area } \\
\text { around } \\
\text { nest } \\
\left(\mathrm{m}^{2}\right)\end{array}$} & \multicolumn{3}{|c|}{$\begin{array}{l}\text { Mean plant abundance } \\
\text { in area around nest }\left(\mathrm{m}^{2}\right)\end{array}$} & \multicolumn{3}{|c|}{$\begin{array}{l}\text { Significance of plant association } \\
\text { differences between species }\end{array}$} \\
\hline & & P.d. & P.m. & P.r. & P.d. - P.m. & P.d.-P.r. & P.m. - P.r. \\
\hline \multirow[t]{6}{*}{ Aristida } & 0.09 & 0.006 & 0.008 & 0 & n.s. & n.s. & n.s. \\
\hline & 0.84 & 0.041 & 0.038 & 0 & n.s. & n.s. & n.s. \\
\hline & 3.24 & 0.178 & 0.128 & 0.093 & n.s. & $\mathrm{n}, \mathrm{s}$. & n.s. \\
\hline & 13.4 & 0.992 & 0.469 & 0.689 & n.s. & n.s. & n.s. \\
\hline & 53.5 & 4.064 & 3.589 & 6.305 & n.s. & n.s. & n.s. \\
\hline & 214.0 & 19.594 & 16.174 & 10.015 & n.s. & n.s. & n.s. \\
\hline \multirow[t]{6}{*}{ Ephedra } & 0.09 & 0.013 & 0.053 & 0.006 & 0.01 & n.s. & 0.05 \\
\hline & 0.84 & 0.145 & 0.324 & 0.120 & 0.05 & n.s. & 0.10 \\
\hline & 3.24 & 0.672 & 0.863 & 0.668 & n.s. & n.s. & n.s. \\
\hline & 13.4 & 3.092 & 3.140 & 3.528 & n.s. & n.s. & n.s. \\
\hline & 53.5 & 12.559 & 13.056 & 16.387 & n.s. & n.s. & n.s. \\
\hline & 214.0 & 51.056 & 53.472 & 57.238 & n.s. & n.s. & n.s. \\
\hline \multirow[t]{6}{*}{ Cryptaniha } & 0.09 & 0.001 & 0 & 0 & n.s. & n.s. & n.s. \\
\hline & 0.84 & 0.011 & 0.004 & 0.017 & n.s. & n.s. & n.s. \\
\hline & 3.24 & 0.038 & 0.002 & 0.044 & n.s. & n.s. & n.s. \\
\hline & 13.4 & 0.149 & 0.036 & 0.120 & n.s. & n.s. & n.s. \\
\hline & 53.5 & 0.466 & 0.203 & 0.372 & n.s. & n.s. & n.s. \\
\hline & 214.0 & 1.899 & 1.294 & 1.517 & n.s. & n.s. & n.s. \\
\hline
\end{tabular}

Table 5

a) Maximum linear foraging distance

\begin{tabular}{llll}
\hline Ant species & $\begin{array}{l}\text { Maximum foraging } \\
\text { distance }(\mathrm{m})\end{array}$ & Variance & $\begin{array}{l}\text { Maximum foraging } \\
\text { area }\left(\mathrm{m}^{2}\right)\end{array}$ \\
\hline P. desertorum & 5.7 & 3.00 & 102.0 \\
$P$. maricopa & 10.8 & 9.30 & 366.2 \\
$P$. rugosus & 14.9 & 3.92 & 697.1 \\
\hline
\end{tabular}

b) Pairwise analysis of differences in foraging distance

\begin{tabular}{ll}
\hline Species pair & Significance of $t$-statistic \\
\hline$P$. desertorum - P. maricopa & $0.009 \mathrm{hs}$ \\
$P$. desertorum - P. rugosus & $0.0000 \mathrm{vhs}$ \\
$P$. maricopa $-P$. rugosus & $0.0000 \mathrm{vhs}$ \\
\hline
\end{tabular}

hs = highly significant $;$ vhs = very highly significant

The mean hydrated weights of the ant species differ significantly from one another (Table 3). Pogonomyrmex desertorum foragers are lighter than $P$. maricopa foragers, which are lighter than $P$. rugosus foragers.

The ant species predominantly use seeds from three plant species, Aristida sp., Cryptantha crassisepala and Ephedra trifurca. The mean abundance of each 


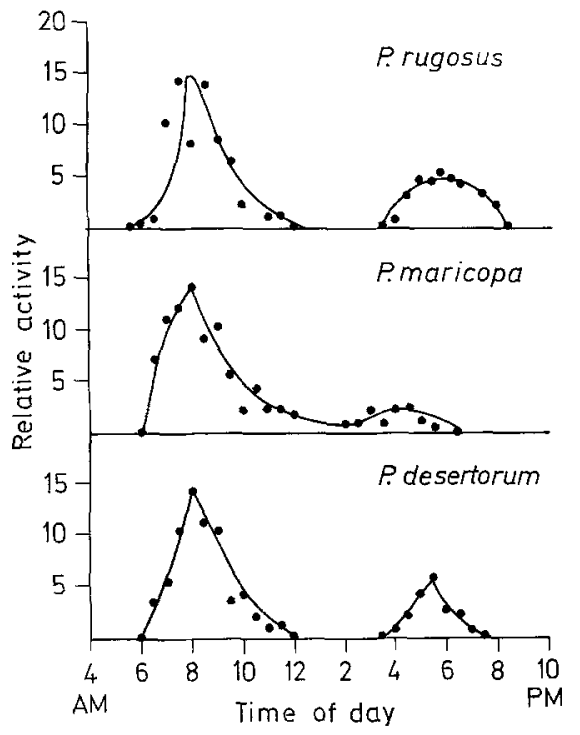

Fig. 1

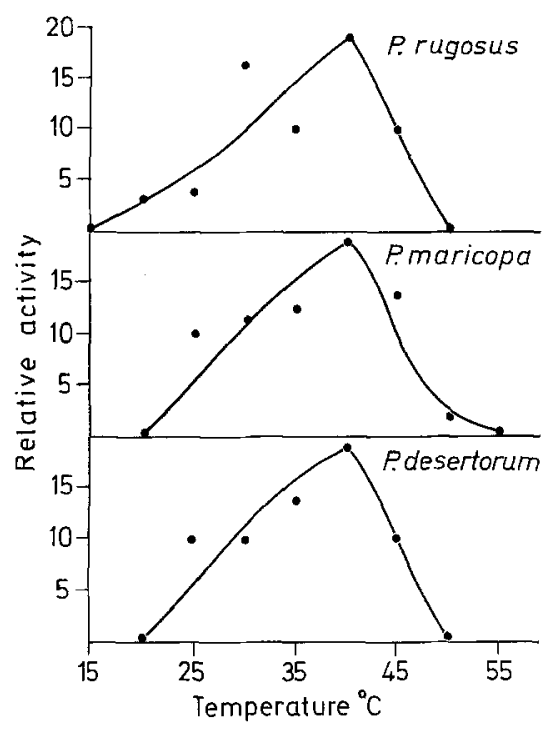

Fig. 2

of these three plant species around the nests of each ant species are presented in Table 4. For the small seed bearing plant, Aristida, and the large seed bearing plant Cryptantha, there are no significant differences in mean abundances between species. However, for the medium seed bearing plant, Ephedra, significant differences do exist. Pogonomyrmex maricopa nests average more nearby Ephe$d r a$ cover than the other ant species. This difference disappears for larger sample areas.

The mean maximum foraging ranges and areas for each ant species are presented in Table 5. These values elucidate differences in available foraging areas. The largest species, $P$. rugosus can forage the farthest. The intermediate size species, $P$. maricopa, can forage an intermediate distance. The smallest species, $P$. desertorum, can forage the shortest distance.

Each of the ant species restricts its foraging to the daylight hours. Despite this basic similarity, certain interspecific differences in relative foraging intensity during this period are apparent (Fig. 1). Pogonomyrmex desertorum and $P$. rugosus each show a very similar bimodal foraging pattern. Foraging is divided into a morning and an afternoon foraging period; the morning period accounting for approximately $75 \%$ of the total activity. No foraging is carried out during the intervening early afternoon period. Differences in their general similarity are observed in relation to the daily onset and cessation of foraging activity. Pogonomyrmex rugosus begins its morning foraging approximately $1 \mathrm{~h}$ earlier and ends its afternoon foraging approximately an hour later than $P$. desertorum, Pogonomyrmex maricopa follows a different foraging pattern. Foraging activity is heavy in the morning (similar to $P$. rugosus and $P$. desertorum) and continues to a limited degree during the early afternoon (as compared to no activity by $P$. 
Table 6. Food collection as a function of time of day

\begin{tabular}{llcl}
\hline & $6: 00-11: 30$ A.M. & $11: 30$ A.M. $-3: 30$ P.M. & $3: 30-8: 30$ P.M. \\
\hline$\%$ of seeds & 24.0 & 1.0 & 75.0 \\
$\%$ of insects & 28.6 & 57.2 & 14.0 \\
\hline
\end{tabular}

Table 7. $\mathrm{LD}_{50}$ values of ant foragers as a function of desiccation stress

\begin{tabular}{|c|c|c|c|}
\hline$T\left({ }^{\circ} \mathrm{C}\right)$ & $\%$ R.H. & Ant species & $\mathrm{LD}_{50}$ \\
\hline 30 & 0 & P. maricopa & 20.25 \\
\hline 30 & 0 & $P$. deseriorum & 9.25 \\
\hline 30 & 0 & P. rugosus & 10.00 \\
\hline 40 & 0 & P. maricopa & 7.50 \\
\hline 40 & 0 & P. desertorum & 5.39 \\
\hline 40 & 0 & P. rugosus & 5.55 \\
\hline 47 & 0 & P. maricopa & 6.52 \\
\hline 47 & 0 & $P$. desertorum & 3.36 \\
\hline 47 & 0 & P. rugosus & 3.30 \\
\hline$T\left({ }^{\circ} \mathrm{C}\right)$ & & Species pair & $\begin{array}{l}\text { Significance of difference } \\
\text { between } L D_{50} \text { values }\end{array}$ \\
\hline 30 & & $\begin{array}{l}P . \text { maricopa }-P . \text { desertorum } \\
P . \text { maricopa }-P . \text { rugosus } \\
P . \text { desertorum }-P . \text { rugosus }\end{array}$ & $\begin{array}{l}0.05 \\
0.05 \\
\text { N.S. }\end{array}$ \\
\hline 40 & & $\begin{array}{l}P . \text { maricopa }-P . \text { desertorum } \\
P . \text { maricopa }-P . \text { rugosus } \\
P . \text { desertorum }-P . \text { rugosus }\end{array}$ & $\begin{array}{l}0.10 \\
0.10 \\
\text { N.S. }\end{array}$ \\
\hline 47 & & $\begin{array}{l}P . \text { maricopa }-P . \text { desertorum } \\
\text { P. maricopa }-P . \text { rugosus } \\
P . \text { desertorum }-P . \text { nugosus }\end{array}$ & $\begin{array}{l}0.05 \\
0.01 \\
\text { N.S. }\end{array}$ \\
\hline
\end{tabular}

rugosus and $P$. desertorum). Foraging builds in intensity in midafternoon and then terminates well before the cessation of activity by the other two species.

Each ant species' maximum foraging intensity is correlated with a $40^{\circ} \mathrm{C}$ surface temperature. Despite this similarity, certain interspecific differences in foraging intensity as a function of surface temperature are seen (Fig. 2). Pogonomyrmex rugosus foragers are more active at low temperatures (in the $15-20^{\circ} \mathrm{C}$ range) than either of the other two species. Pogonomyrmex maricopa foragers are more active at high temperatures (in the $50-55^{\circ} \mathrm{C}$ range) than either of the other two species.

The level of insect and seed items which are collected during different periods of the day are presented in Table 6. Seeds are collected mainly during the morning and late afternoon periods. Insect items are mainly collected in the early afternoon period. 
The survivorship capabilities of the three ant species, under conditions of desiccation stress, show statistically significant interspecific differences (Table 7). Over all experimental conditions, $P$. maricopa foragers have a higher $\mathrm{LD}_{50}$ value than the foragers of either of the other two species. The LD $_{50}$ values of $P$. desertorum and $P$. rugosus do not significantly differ.

\section{Discussion}

Under conditions of resource limitation, coexistence of several species should depend upon the differential utilization of the limited resource. In this Upper Sonoran Grassland Community, three species of harvester ants coexist on an apparently limited food resource. As expected, the ant species partition the available food. This partitioning is facilitated by interspecific differences in morphology, physiology and micro-habitat utilizations.

The three ant species divide the available seeds according to size and, correspondingly, weight. This division is facilitated by interspecific differences in the size of foragers and, consequently, their ability to handle various size prey items. This position is supported by two lines of evidence. First, there is a positive correlation between the mean seed weight collected by an ant species and the mean forager weight of the ant species. Second, a multiple of approximately 1.6 is found between the mean weight of foragers of one ant species and the next larger species. This value is similar to values found in other natural communities, in which the food resource is divided according to the ability of the species to handle various size food items (Levins, 1968; Culver, 1972; Hespenheide, 1971).

The division of seeds according to size is also facilitated by interspecific differences in microhabitat nest locations. Pogonomyrmex maricopa nests are more frequently located very close to or directly beneath Ephedra trifurca individuals than are the nests of the other two ant species. Since Ephedra trifurca is the major source of medium size seeds, $P$. maricopa's close proximity aids in its ability to acquire the major portion of this seed size class. Whether this pattern of nesting is a consequence of an active choice by founding queens or a result of differential nest survival is not known. However, this situation does aid in partitioning the seed resource. The medium size ant, $P$. maricopa, is able to secure a higher percentage of the medium size seeds, which it is presumably better able to handle.

Insect items are the other major portion of the food resource. The differential use of these items is facilitated by interspecific differences in foraging patterns. Insect items are primarily collected during the noon-early afternoon foraging period. Only $P$. maricopa workers forage during this time period. Not surprisingly, $P$. maricopa almost monopolizes the insect segment of the food resource.

The mechanism underlying the different foraging patterns illustrated by the ant species appears to be differential desiccation resistance. Under conditions of desiccation stress, $P$. maricopa foragers can survive the longest. This higher resistance to desiccation is correlated with an unique ability to forage during the hottest portions of the day and, consequently, to collect the temporarily 
available insect prey items. The temporary availability of insect items is, perhaps, also due to desiccation stress. Insects trapped in the open during the mid-day period may become dehydrated and subject to easy capture and/or death.

\section{References}

Ahearn, G.A., Hedley, N.F.: The effects of temperature and humidity on water loss in two desert Tenebrionid beetles, Eleodes armata and Cryptoglossa verrucosa. Comp. Biochem. Physiol. 30, $739-749$ (1969)

Bernstein, R.A.: Seasonal food abundance and foraging activity in some desert ants. Am. Nat. 108, 490-498 (1974)

Brown, J.H., Liebermann, G.A. : Resource utilization and coexistence of seed-eating desert rodents in several dune habitats. Ecology 54, 788-797 (1973)

Cody, M.L.: On the methods of resource division in grassland bird communities. Am. Nat. 102, $107-147$ (1968)

Culver, D.C.: Analyses of simple cave communities : niche separation and species packing. Ecology 51, 949-958 (1970)

Culver, D.C.: A niche analysis of Colorado ants. Ecology 53, 126-131 (1972)

Davidson, D.W. : Species diversity and community organization in desert seed-eating ants. Ecology 58, $711-724$ (1977)

Gause, G.F.: The struggle for existence. Baltimore: Williams and Wilkins 1934

Hespenheide, H.A.: The selection of seed size by finches. Wilson Bull. 78, 191-197 (1966)

Hespenheide, H.A.: Food preference and the extent of overlap in some insectivorous birds, with special reference to the Tyronnidae. Ibis 113, 59-72 (1971)

Levins, R.: Evolution in changing environments: some theoretical explorations. Princeton, N.J.: Princeton Univ. Press 1968

Lotka, A.J. : Elements of mathematical biology. Baltimore: Williams and Wilkins 1925

MacArthur, R.H.: Population ecology of some warblers of northeastern coniferous forests. Ecology 39, 599-619 (1958)

MacArthur, R.H. : Geographic ecology: patterns in the distribution of species. New York: Harper and Row 1972

Morista, M.: Measuring the dispersion of individuals and analyses of the distributional patterns. Mem. Fac. Sci. Kyushu Univ. (E) 2, 215-235 (1959)

Orians, G.H., Horn, H.S.: Overlap in food and foraging of four species of blackbirds in the potholes of central Washington. Ecology 50, 930-938 (1969)

Paine, R.: The measurement and application of the calorie to ecological problems. Ann. Rev. Ecol. Syst. 2, 145-164 (1971)

Rosenzweig, M.L., Steiner, P.W.: Population ecology of desert rodent communities: body size and seed-husking as bases for heteromyid coexistence. Ecology 51, 217-224 (1970)

Vance, R.R.: Competition and mechanism of coexistence in three sympatric species of intertidal hermit crabs. Ecology 53, 1062-1074 (1972)

Volterra, V.: Fluctuations in the abundance of a species considered mathematically. Nature 118, $558-560(1926)$

Volterra, V.: Lecons sur la theorie mathematique de la lutte pour la via. Cahiers Scientifique 7. Paris: Gauthier-Villars 1931 